\title{
MULHERES QUE VIVENCIARAM VIOLÊNCIA CONJUGAL: CONCEPÇÕES SOBRE SUAS AÇÕES, 0 HOMEM AUTOR E A EXPERIÊNCIA
}

\author{
WOMEM WHO EXPERIENCED MARITAL VIOLENCE: CONCEPTIONS \\ ON THEMSELVES, THE MAN WHO PRACTICED THE VIOLENCE \\ AND THE VIOLENCE
}

PAOLA RODEGHERI

GALELI

Psicóloga - Universidade

Federal de Ciências da

Saúde de Porto Alegre, RS,

Brasil.

\section{CLARISSA DE ANTONI}

Professora Associada I -

Universidade Federal de

Ciências da Saúde de Porto

Alegre, RS, Brasil.
Recebido em: 08/04/2018 Aprovado em: 01/06/2018
RESUMO: Esse estudo qualitativo buscou compreender a violência conjugal por meio das concepções de cinco mulheres, de 23 a 36 anos, que estavam envolvidas em processo judicial contra o homem autor da violência e afastadas deles há tempo mínimo de oito meses. Foi aplicado questionário com dados sociodemográficos e uma entrevista semiestruturada englobando aspectos do relacionamento, da violência, denúncia e período após separação. Após análise, originaram-se três categorias sobre as concepções dessas mulheres em relação a: (a) suas próprias ações; (b) o homem autor de violência e (c) a violência. Os resultados revelam compreensão sobre 0 fenômeno da violência durante o período em que a vivenciavam, por vezes, não qualificando as ações como abusivas, favorecendo a manutenção da violência no subsistema conjugal. Pode-se perceber concepção mais crítica durante o processo de afastamento do homem autor da violência. Nesse estudo, a forma de encerrar o ciclo de violência foi rompendo a relação.

PALAVRAS-CHAVE: violência contra a mulher; mulher; conjugalidade; homem.
ABSTRACT: This qualitative study aimed to understand conjugal violence through the conceptions of five women who have been through this in their recent past, aged 23-36, who were involved in a lawsuit against the man who practiced the violence and away from them for at least eight months. A questionnaire was applied with socio-demographic data and a semi-structured interview covering aspects about the relationship, violence and time after separation. Three categories were originated on the analysis focusing the conceptions about (a) themselves, (b) the man who practiced the violence, and (c) the violence. The results show an inappropriate understanding during the period they were suffering, often minimizing and not conceiving the attitudes as abusive. This conception was keeping the violence on the marital subsystem. However, it's possible to conceive a critical conception during the breaking up process. In this article, the way to stop the violence was breaking up the relationship.

KEYWORDS: violence against women; women; conjugality; men.

\section{INTRODUÇÃo}

O fenômeno da violência conjugal contra mulheres tem sido foco de pesquisas e de desenvolvimento de programas para reduzir os agravos físicos, psicológicos e sociais decorrentes dessa vivência (Gomes et al., 2012; Miranda, Paula, \& Bordin, 2010; Silva, Gomes, Acosta, Barlem, \& Fonseca, 2013). Entretanto, ainda há muito a ser compreendido sobre esse fenômeno.

Essa realidade pode ser considerada como de extrema relevância a partir de seus números. Em nosso país, contabiliza-se 4,8 assassinatos a cada 100 mil mulheres, número que coloca o Brasil no $5^{\circ}$ lugar no ranking de países nesse tipo de crime. Além 
disso, o levantamento realizado pela Secretaria de Políticas para as Mulheres da Presidência da República (SPM-PR) aponta que a Central de Atendimento à Mulher Ligue 180, no $1^{\circ}$ semestre de 2016, atendeu a 67.962 relatos de violência. Entre esses relatos, 51,06\% corresponderam à violência física; $31,10 \%$, violência psicológica; $6,51 \%$, violência moral; $4,86 \%$, cárcere privado; $4,30 \%$, violência sexual; $1,93 \%$, violência patrimonial; e $0,24 \%$, tráfico de pessoas. Os relatos de violência apontam que, em $81 \%$ dos casos, os autores das agressões são pessoas que têm ou tiveram vínculo afetivo com as vítimas (SPM, 2016). Esses dados alarmantes revelam que a violência conjugal não é apenas questão de relação interpessoal, mas social e de saúde pública, considerando a severidade das consequências para todos os envolvidos.

Para além dos dados, entende-se que os números relativos a esse tipo de violência podem, inclusive, não corresponder à realidade por existir uma subnotificação dos mesmos, uma vez que ocorre no ambiente doméstico, compreendido como privado; e, portanto, se mantém assim uma invisibilidade sobre esses fatos (Gomes et al., 2012). Ademais, as mulheres têm dificuldades em delatar seus companheiros pela dinâmica relacional estabelecida pelo casal que alterna situações amorosas, de arrependimento do homem autor de violência e perdão da pessoa em situação de violência, com situações de tensão e de descontrole sobre os atos (Falcke, Boeckel, Arpini, \& Madalena, 2015).

A violência conjugal atinge a mulher de maneira física, psicológica, sexual e social (Falcke et al., 2015; Gomes, 2012). Além disso, engloba todas aquelas formas nas quais se oprimem, impossibilitam ou se violam as garantias individuais. Por esse motivo, ob- serva-se que todas as definições concordam que a violência se configura como qualquer ato exercido contra a dignidade da mulher, independentemente de suas origens (Casique \& Furegato, 2006). O medo das frequentes ameaças e agressões juntamente com a vergonha por se manter na relação fazem com que as mulheres não falem da violência vivida às pessoas mais próximas e, da mesma maneira, aos serviços de saúde. Por outro lado, pode ocorrer um fenômeno denominado "anestesia relacional", que se configura como sentimentos, ideias e ações que contribuem para a manutenção da situação de violência, especialmente pela negação ou naturalização da mesma (Guimarães \& Diniz, 2017). Além disso, essa forma de relação pode levar ao "aprisionamento" de ambos os cônjuges a essa dinâmica conjugal.

Os reflexos da violência transformam a configuração das suas redes de apoio social, de maneira que se torna cada vez mais restrita e reduzida, com pouco poder para oferecer apoio (Dutra, Prates, Nakamura, \& Villela, 2013). Como afirmam esses autores, também há o fato de as mulheres ainda atribuírem suma importância ao casamento, resultando num sentimento de obrigação de manter esse compromisso ou vínculo.

Como descrito, a violência conjugal pode acarretar diferentes prejuízos à vida da mulher e é compreendida de maneira singular por cada uma delas. Muitos fatores estão associados e influenciam na manutenção ou rompimento desta violência. A maneira como a mulher percebe e vivencia essa situação pode favorecer o enfrentamento da violência e até evitar futuras situações de risco.

Nesse artigo, a violência é entendida como o uso intencional da força física ou de poder, seja real ou como ameaça 
contra si próprio, outra pessoa ou um grupo ou uma comunidade, que resulte ou tenha grande possibilidade de resultar em lesão, morte, dano psicológico, deficiência de desenvolvimento ou privação (OMS, 2002). Quando se trata da violência contra a mulher com autoria de um homem especificamente, é comum que decorra de relações desiguais entre masculino e feminino, ou seja, tomando-se por base a categoria gênero (Gomes et al., 2012). Devido a isso, optou-se por selecionar mulheres que sofriam violência conjugal advinda de homens, seus parceiros íntimos, e que haviam rompido a relação em função da violência. $O$ objetivo da pesquisa foi conhecer as concepções sobre suas próprias ações, sobre o homem autor de violência e sobre a violência. Neste estudo, concepção se refere à maneira como a pessoa concebe, percebe, julga, conceitua e qualifica os acontecimentos vivenciados.

\section{MÉTODO}

O presente estudo é de caráter qualitativo. Esse tipo de abordagem engloba de forma ampla o fenômeno estudado pois, como afirma Flick (2009), na pesquisa qualitativa os objetos de estudo não são reduzidos a variáveis simples, mas sim representados em sua totalidade, dentro dos seus contextos cotidianos.

Participaram do estudo cinco mulheres que vivenciaram situações de violência cujo autor havia sido o homem com que se relacionavam, com idades entre 23 e 36 anos, procedentes da cidade de Porto Alegre, que realizaram notificação sobre os fatos e estavam separadas do homem autor de violência no momento da entrevista para coleta de dados. Nesse estudo, o tempo de separação variou entre oito meses e quatro anos. O tempo de relacionamento foi entre um mês e dezesseis anos. Quatro delas possuíam filhos, sendo que duas das participantes tinham filhos com o homem autor de violência em questão. Quanto à formação, duas participantes possuíam Ensino Médio Completo, duas possuíam formação técnica e uma possuía superior completo. A renda das participantes variou entre 2 a 8 salários mínimos vigentes. Foram utilizados nomes fictícios para cada uma das participantes a fim de preservar a identidade. A Tabela da página a seguir contém os dados das participantes.

$\mathrm{O}$ acesso às participantes ocorreu através do $1^{\circ}$ Juizado da Violência Doméstica e Familiar Contra a Mulher, localizado no Foro Central, na cidade de Porto Alegre/RS. Para contato, foram feitas buscas ativas nos registros locais dos processos em andamento para contato telefônico, assim como divulgação na sala de espera feita pelas pesquisadoras, enquanto as mesmas aguardavam para audiências relacionadas à judicialização da violência. $\mathrm{O}$ processo de divulgação durou quatro meses. O projeto foi aprovado pelo Comitê de Ética em Pesquisa da Universidade Federal de Ciências da Saúde de Porto Alegre, sob o parecer número 1.029.203, e segue as normas de pesquisa com seres humanos.

Os instrumentos utilizados foram um questionário sociodemográfico (idade, escolaridade, ocupação, nível socioeconômico, número de filhos, com quem reside etc.) e uma entrevista semiestruturada, ambas elaboradas pelas pesquisadoras. O roteiro consistiu em questões sobre a história do casal, a situação de violência, a denúncia, os tipos de atendimentos recebidos, fatores facilitadores ou que possam dificultar o enfrentamento da violência, o processo de decisão pela separação, assim como a situação atual da mulher. 
Tabela 1. Dados demográficos e do relacionamento das participantes

\begin{tabular}{|c|c|c|c|c|c|c|c|}
\hline $\begin{array}{l}\text { Nome } \\
\text { fictício }\end{array}$ & Idade & $\begin{array}{l}\text { Nível de } \\
\text { Escolari- } \\
\text { dade }\end{array}$ & $\begin{array}{c}\text { Renda } \\
\text { em } \\
\text { salário } \\
\text { mínimo } \\
\text { vigente }\end{array}$ & $\begin{array}{l}\text { Tempo } \\
\text { de rela- } \\
\text { ciona- } \\
\text { mento }\end{array}$ & $\begin{array}{l}\text { Tempo } \\
\text { de afas- } \\
\text { tamento }\end{array}$ & Filhos & $\begin{array}{c}\text { Tipo de } \\
\text { violência } \\
\text { sofrida }\end{array}$ \\
\hline $\begin{array}{c}\text { P5 } \\
\text { Luisa }\end{array}$ & $\begin{array}{c}36 \\
\text { anos }\end{array}$ & $\begin{array}{l}\text { Ensino } \\
\text { Médio }\end{array}$ & 2 & 4 anos & $\begin{array}{c}2 \text { anos } \\
\text { e } 10 \\
\text { meses }\end{array}$ & 4 & $\begin{array}{l}\text { Violência } \\
\text { física e } \\
\text { psicoló- } \\
\text { gica }\end{array}$ \\
\hline $\begin{array}{c}\text { P2 } \\
\text { Paula }\end{array}$ & $\begin{array}{c}33 \\
\text { anos }\end{array}$ & $\begin{array}{l}\text { Ensino } \\
\text { Médio }\end{array}$ & 1.6 & 16 anos & 3 anos & 3 & $\begin{array}{l}\text { Violência } \\
\text { física e } \\
\text { psicoló- } \\
\text { gica }\end{array}$ \\
\hline $\begin{array}{c}\text { P4 } \\
\text { Vanessa }\end{array}$ & $\begin{array}{c}23 \\
\text { anos }\end{array}$ & $\begin{array}{l}\text { Ensino } \\
\text { Técnico }\end{array}$ & 1.5 & 2 anos & 7 meses & Não & $\begin{array}{l}\text { Violência } \\
\text { física e } \\
\text { psicoló- } \\
\text { gica }\end{array}$ \\
\hline $\begin{array}{c}\text { P1 } \\
\text { Milena }\end{array}$ & $\begin{array}{c}33 \\
\text { anos }\end{array}$ & $\begin{array}{l}\text { Ensino } \\
\text { Superior }\end{array}$ & 4.5 & 1 ano & $\begin{array}{l}1 \text { ano e } \\
6 \text { meses }\end{array}$ & 1 & $\begin{array}{l}\text { Stalking e } \\
\text { violência } \\
\text { psicoló- } \\
\text { gica }\end{array}$ \\
\hline $\begin{array}{c}\text { P3 } \\
\text { Aline }\end{array}$ & $\begin{array}{c}33 \\
\text { anos }\end{array}$ & $\begin{array}{l}\text { Ensino } \\
\text { Médio }\end{array}$ & 3 & 2 meses & Um ano & 1 & $\begin{array}{l}\text { Violência } \\
\text { física, psi- } \\
\text { cológica } \\
\text { e cárcere } \\
\text { privado }\end{array}$ \\
\hline
\end{tabular}

Após a transcrição das entrevistas, os dados foram submetidos à Análise de Conteúdo Temática, a fim de identificar particularidades e semelhanças quanto aos temas investigados. Essa metodologia consiste em descobrir os núcleos de sentido que compõem a comunicação, cuja presença ou frequência denotem significados do objeto analítico visado. Para a realização da mesma, conta-se com três etapas: a pré-análise, a exploração do material e o tratamento dos resultados obtidos e interpretação dos mesmos (Bardin, 2009; Minayo, 2010). Os resultados da categorização foram submetidos a três juízes independentes com conhecimento sobre o tema, que analisaram as categorias e os conteúdos, a fim de validá-los em conjunto com seus exemplos.

\section{RESULTADOS E DISCUSSÃO}

A partir da análise dos dados obtidos, foram propostas três categorias relacionadas às concepções sobre a situação que envolvia a violência. Observa-se que as participantes relataram a violência sofrida e os diferentes fatores presentes naquela época que fomentaram a manutenção da relação, assim como aqueles que possibilitaram o rompimento da mesma. Uma visão mais crítica sobre os fatos somente foi 
possível quando as mesmas se encontravam em processo de afastamento dos homens autores de violência. As categorias encontradas envolviam as concepções dessas mulheres sobre: (a) suas próprias ações, (b) o homem autor de violência e (c) a violência.

\section{CONCEPÇÕES DAS MULHERES SOBRE SUAS PRÓPRIAS AÇÕES}

Essa categoria diz respeito à concepção das participantes sobre elas mesmas durante a vivência da relação em que havia violência e durante o processo de enfrentamento. Nesse momento, surgem entrelaçados os constructos conhecidos por autoconceito e autoestima. O autoconceito é definido nesse estudo como a percepção do indivíduo sobre ele mesmo e que é formada a partir das experiências e de suas interpretações sobre seu ambiente (Shavelson \& Bolus, 1982), sendo influenciado pelos papéis desempenhados, identidades sociais formadas, comparações com os outros, êxitos e fracassos, o julgamento de pessoas próximas e a cultura circundante (Myers, 2014). Já autoestima se refere a um aspecto avaliativo do autoconceito, consistindo num conjunto de pensamentos e sentimentos relacionados a si mesmo. Segundo Hutz e Zanon (2011), trata-se de uma orientação positiva (autoaprovação) ou negativa (depreciação). Tanto o autoconceito como a autoestima estão relacionados a um determinado momento, podendo ser mutáveis conforme situações, interações com os outros e o processo de autoconhecimento.

Durante o período em que as participantes mantinham algum tipo de relacionamento com o ex-cônjuge, pode-se identificar que o autoconceito estava vinculado ao conceito atribuído pelo outro, como observado nos exemplos a seguir das falas das participantes:

Nossa, eu me senti um lixo. Um nada... Tu se sente, assim, como se tu fosse realmente aquilo que ele está falando que tu és... Chegava num ponto que eu concordava com ele que eu era tudo aquilo que ele estava me dizendo. (Luisa)

Esse aspecto do autoconceito, especificamente, também é enfatizado por Milena, que afirma: "Porque é muito difícil tu se enxergar (...) eu me via muito distorcida, muito ruim, muito feia". Essa concepção poderia facilitar uma manutenção da violência por levar a um questionamento sobre seus próprios valores e sobre a plausibilidade dos atos do homem autor de violência, estabelecendo a homeostase de funcionamento do subsistema conjugal com base numa disputa de poder e na subjugação.

Frente a muitos acontecimentos que ocorrem na relação conjugal, um fator de destaque é o registro da violência em forma de marca física. Ao se ver com lesões, pode aproximar-se de seu sofrimento emocional, como afirma Paula:

Então eu pensei várias coisas, mas o que me tomou mesmo e fez tomar a decisão foi me olhar no espelho e ver o jeito que eu estava me escondendo do trabalho do jeito que eu estava. Eu achava que aquilo não era certo.

Cabe mencionar a valorização de si mesmas, assim como a concepção sobre a não tolerância da violência e o desejo de uma situação diferente, que surgem também como uma demonstração das mudanças socioculturais relacionadas aos papéis de gênero, para além de uma mudança 
individual. Como afirmam Falcke et al. (2009), as manifestações de discriminação e de violência contra as mulheres também podem ser compreendidas como resultantes de relações de poder historicamente desiguais, colocando as mulheres em posição inferior, de maneira a favorecer a violência. No entanto, as alterações que vêm surgindo nesse cenário de discussão sobre direito da mulher e de uma busca por relações não pautadas na subordinação de um gênero ao outro justificam essa nova concepção da mulher. Ou seja, percebendo a violência como não cabível e enxergando-se de maneira a não aceitar e não perpetuar esse sistema de desigualdade.

Apesar disso, quando conseguem romper com o ciclo de violência, parece que as mulheres conseguem olhar para si mesmas e se questionar quanto à continuidade daquela relação. Então a tomada de decisão sobre a notificação da violência e o afastamento do homem autor de violência parecem ser benéficos para a mulher. Assim, há possibilidade de indagações sobre sua integridade física e emocional, como indicam as participantes:

Bater em mim, jamais eu vou aceitar de me bater, nunca. Não nasci pra isso (...) acho que uma pessoa tem que ser livre, tu tem que poder falar, conversar, tu tem que poder fazer o que tu sentir vontade. Imagina, tu não poder falar com ninguém?... não quero isso pra mim. (Aline)

Nesse dia que a gente terminou, eu falei que eu não amava mais ele, que eu estava de saco cheio daquela vida, (...) que não ia ficar com um cara que bate em mulher, que eu não nasci pra isso, não nasci pra apanhar de homem (...) deixei minhas malas lá porque o que importa era $e u$, as roupas não faziam diferença pra mim”. (Vanessa)

No caso destas mulheres, a maneira de romperem a relação de violência foi rompendo o relacionamento. Durante o processo de afastamento do homem autor de violência, percebe-se uma problematização quanto a si mesma, emergindo um autoconceito mais independente do outro e autoestima mais elevada, como afirma Milena:

Da minha valorização enquanto mulher, enquanto mãe... enquanto pessoa. De saber que eu posso e mereço algo melhor... né? De qualidade. Que eu sei escolher (...) E foi muito bom eu ficar comigo mesma. Coisa que eu não sabia também. Então: não, eu posso, é bem legal eu comigo mesma, eu gosto de mim.

Essa concepção pode atuar como fator protetivo para o enfrentamento da situação de violência, à medida que favorece a mulher a se perceber de forma valorada, incluindo, em alguns casos (como os pesquisados), o rompimento da relação.

\section{CONCEPÇÕES DAS MULHERES SOBRE 0 HOMEM AUTOR DE VIOLÊNCIA}

A categoria "Concepções sobre homem autor de violência" engloba as ideias que as mulheres apresentam a respeito dos seus ex-parceiros íntimos, assim como os comportamentos identificados pelas mulheres na relação conjugal. As participantes tentam explicar as agressões por meio de duas diferentes e distintas concepções. A primeira se relaciona à concepção que tinham no período em que a violência ocorria e se relaciona a um desconhecimento sobre seu ex-companheiro; e 
a segunda refere-se ao momento em que se encontram afastadas dos homens autores de violência, tendo uma compreensão de que seus companheiros apresentavam comportamentos agressivos e manipuladores.

No período em que estavam vivendo a violência, as mulheres tinham uma série de explicações para os comportamentos dos ex-parceiros como, por exemplo, que o ciúme era uma forma de manifestação de cuidado e amor. Uma dessas concepções é sobre o tipo de controle exercido por parte do homem autor de violência e que não era compreendido de forma crítica, conforme a seguinte fala: "eu achava que ele tava fazendo aquilo... nunca porque ele era louco, psicopata" (Aline), assim como na fala de Vanessa:

Ele fez isso (...) eu tô com medo por isso, como eu sei que ele é uma pessoa agressiva, uma pessoa que tem uma ficha extensa na polícia e que eu só fiquei sabendo depois que eu terminei com ele, quando fui dar queixa.

Segundo Paula, por exemplo, durante o período inicial da relação, ela não cogitava que ele pudesse apresentar comportamentos violentos: "quando ele começou a me agredir foi porque eu pedi a separação (...) eu não sei o que levou ele a pensar que me batendo eu ia continuar com ele, eu acho que até piorou, piorou mesmo".

Uma noção que explicou as expressões de ciúme e possessividade sustentou-se na interpretação de serem manifestações de amor ou de cuidado. Como retratado pelo relato de Milena: "E ele sempre demonstrando um comportamento mais possessivo (...) e eu achando legal, achando que ele gostava de mim pra mostrar isso". Quanto ao ciúme como demonstração do amor, indica Vanessa:
Eu pensava que ele era muito ciumento, isso era visivel, ele controlava minha roupa, ele não deixava usar legging, não dava pra usar blusa decotada, não deixava nada. E eu achava (...) que ele me amava muito e que tava com ciúmes, e queria que eu, sei lá, que eu me guardasse só pra ele.

Nesse sentido, elas não percebiam os comportamentos de seus companheiros de modo que as levasse a romper a dinâmica de violência.

Segundo Antezana (2012), na relação, os homens podem demonstrar um comportamento abusivo que os fazem sentir e agir de forma diferente. Naquele momento, a maneira como as mulheres interpretavam os comportamentos abusivos favorecia a manutenção do ciclo da violência pelo fato de subestimarem o grau de severidade dos mesmos. Nesta mesma direção, da parte dos homens, Guimarães e Diniz (2017) revelam que eles não compreendem o controle e o ciúme como forma de coagir, mas como meios naturais e constituintes de demonstrar sua soberania. Assim, podem explicar sua conduta, que aponta no sentido de culpabilização da mulher.

Esse entendimento sobre eles mesmos transcende essa visão individual, também sendo encontrada em nível social. Ou seja, esses comportamentos relacionados são enaltecidos pela sociedade patriarcal atual pautada nas desigualdades, na dominação e que coloca a virilidade como atributo a ser almejado por um homem. Da mesma forma, o homem se reconhece como vítima das situações e de sua parceira, numa dinâmica de culpabilização e não sendo empático em relação àqueles ao seu redor. Essa percepção compromete a vivência de relacionamentos sem violência e da resolução de conflitos conjugais de forma pacífica. 
É possível destacar que ocorre uma modificação na visão das mulheres sobre seus antigos companheiros durante o processo de afastamento dos mesmos, pautada numa mudança de representação sobre a violência. Neste momento, as participantes apontam as atitudes do homem autor de violência não como uma forma de amor e interação, mas desmedidos e abusivos. Percebe-se no processo de rompimento da relação uma ressignificação da compreensão sobre os ex-parceiros. Essa ressignificação pode ter tido um papel protetivo, pois pode permitir uma compreensão da dinâmica da relação com o homem que anteriormente ocupava o papel de companheiro. Para as mulheres pesquisadas, essa nova concepção as levou à ruptura no ciclo da violência, através do afastamento do homem autor de violência.

\section{CONCEPÇÕES DAS MULHERES SOBRE A VIOLÊNCIA}

Essa categoria aborda as concepções das mulheres sobre a violência, tendo emergido a partir de questões sobre as situações de violência, fatores envolvidos no enfrentamento da violência e de decisão quanto à notificação e separação do homem autor da violência. Os relatos descritos apontam que os atos não eram qualificados como violentos antes da notificação, conforme indica Milena: "Não, não tenho motivo forte pra isso [a denúncia], eu não qualificava o evento como grave". A questão descrita está em consonância com o encontrado na literatura, como indicam Schraiber et al. (2007), no que diz respeito ao não reconhecimento da noção de violência para nomear as situações de agressões vivenciadas.

$\mathrm{Na}$ mesma direção, Guimarães e Diniz (2017) refletem sobre a negação e minimização da violência, ao afirmarem que a construção social entre público e privado é dissociada, sendo todos os acontecimentos da esfera privada (doméstica) tidos com menor valia. A amenização dos comportamentos violentos aparece na compreensão relacionada a uma intencionalidade não violenta dos atos do parceiro, como no discurso de Aline:

Não levei muito a sério, eu disse ah, eles também tão exagerando, o guri não é tudo isso... imagina, ele só bateu em mim sem querer (...) todo mundo erra, eu posso também errar um dia, posso estar mais estressada do que o normal.

Também como demonstração de amor, como indica Milena:

Eu achava que ele me amava ultra, isso eu não tinha dúvida, era amor de verdade, porque ele fazia qualquer coisa por mim... ele me seguia, ele ia atrás de mim, ele me ligava de qualquer lugar... pra querer ouvir minha voz, e falava coisas extremamente agradáveis e eu me sentia amada por ele.

Assim como indica Aline: "ele tava apaixonado e dizendo que ia viver só pra mim, imagina que delícia”. Dessa maneira, a concepção das mulheres durante a vivência das agressões atuava como risco. Como indicam Leite, Moura e Penna (2013), isso pode dificultar a tomada de decisão pelo rompimento da relação.

No entanto, durante o processo de afastamento do homem autor de violência, passaram a compreender e a qualificar os eventos de outra maneira. Assim, essa concepção pode atuar de forma protetiva para o enfrentamento da situação que, no caso delas, deu-se pelo rompimento da relação e à continuidade do processo judicial contra os homens
Mulheres que vivenciaram violência conjugal: concepções 8 sobre suas ações, o homem autor e a experiência Paola Rodegheri Galeli Clarissa De Antoni 
autores de violência. Tal situação surge na fala de Milena, na qual se evidencia a transformação dessas concepções decorrentes de um afastamento:

Eu enxergo ele mais limpo, como ele é e sem o sentimento que eu tinha por ele que é doentio, é assim que eu qualifico. Não é nem amor, é uma coisa doente. (...) O que me ajuda? A minha clareza de olhar de fora, né? Porque se distanciou tanto fisicamente e agora, muito mais sentimentalmente. Então, daí eu vejo melhor e me sinto segura.

A categoria sobre a violência revela a visão que as participantes apresentam sobre os aspectos relacionados à situação de violência dentro da dinâmica conjugal. $\mathrm{O}$ que se destaca durante essa exposição é que as agressões são interpretadas pelas participantes que, por vezes, não as compreendem como violência. Durante o afastamento do homem autor de violência, as participantes parecem construir uma outra concepção sobre si, sobre o homem autor de violência e sobre a violência.

\section{CONCLUSÃO}

Conclui-se que essas mulheres que notificaram judicialmente situações de violência nas suas relações conjugais por seus parceiros íntimos e que se separaram percebem os fatos de forma diferenciada entre o passado, mesmo que recente, e o seu presente (momento da entrevista). Quando estavam vivenciando a violência, não conseguiam percebê-la como abusiva. Compreendiam o comportamento do ex-cônjuge como uma manifestação de cuidado e não de controle. Além disso, as vivências tiveram impacto sobre a autoestima, porque seu autoconceito era constituído majoritariamente pelo olhar do outro, neste caso, pelo olhar do homem autor de violência. Relacionado a isto, o autor as mantinha na relação, mesmo com humilhações e degradações; talvez, inclusive, as mantivesse por isto.

De maneira geral, destaca-se o conceito de "anestesia relacional" apresentado por Ravazzola (Guimarães \& Diniz, 2017), na qual a banalização das violências nas relações conjugais impossibilita uma ação mais ativa para impedir a submissão a essas violências. Sendo assim, se mantém a homeostase no subsistema conjugal, mesmo que essa forma de interação seja opressora.

A mudança que ocorre na forma de perceber as violências por parte da mulher, que se dá, como nos casos pesquisados, com o rompimento da relação, é de extrema importância, pois possibilita romper com o ciclo de violência. Também permite romper com o legado e o mito - para as próximas gerações - de que a violência é inerente às relações. Nas situações retratadas, essa nova dimensão sobre as vivências tornou-se possível quando as situações já pareciam insustentáveis ou de alto nível de gravidade. Dessa forma, torna-se essencial que sejam realizados estudos e abordagens que possam compreender como intervir nesse funcionamento de maneira preventiva ou a reduzir os danos, evitando que a violência se perpetue e seja disseminada em nossa sociedade. Talvez considerando até que seja possível enfrentar a violência sem que seja necessário o rompimento da relação.

\section{APONTAMENTOS ADICIONAIS}

Esse estudo ouviu mulheres que denunciaram a situação de violência conjugal e se separaram dos compa- 
nheiros. A partir dos relatos, analisou-se esses fatores pensando sobre a dinâmica das relações conjugais violentas. Embora haja estudos sobre o tema, a compreensão sobre esse fenômeno ainda necessita de pesquisas contextuais e que elucidem as dificuldades enfrentadas pelas mulheres após o rompimento dessas relações abusivas refletindo, então, se esta é uma resposta suficiente ou a única possível.

Foram encontradas dificuldades na coleta dos dados, no que diz respeito ao acesso às participantes. Evidenciou-se a ausência de dados completos no sistema referentes ao cadastro e aos processos em andamento, assim como o fato de as participantes não residirem no mesmo local ou não possuírem o número de telefone disponível no sistema. Na etapa seguinte à marcação das entrevistas, muitas delas não compareceram no momento agendado para a coleta de dados. Possivelmente, essas participantes repetidamente recontam os fatos nas diversas instituições que passam durante os trâmites processuais e, muitas vezes, pode ser difícil acessarem esses sentimentos e estarem confortáveis para expressá-los ou, ainda, encontrarem conforto por parte daqueles que as ouvem. Talvez este fato esteja relacionado à dificuldade que as mesmas tiveram em acessar um serviço de acolhimento qualificado. Por isto até, nas diferentes etapas em que se esteve em contato com as participantes, foram tomadas as medidas necessárias e cabíveis para evitar que fossem expostas a desconfortos ao abordar a situação. Informalmente, as participantes entrevistadas avaliaram esse momento como uma possibilidade de expressar sentimentos e pensamentos relacionados às vivências.

Quanto às limitações do estudo, optou-se pelo afastamento das participantes do homem autor de violência por um período de mais de oito meses do momento da entrevista, pressupondo então que, assim, se poderia pensar melhor as relações entre rompimento da relação e maneira de cessação da violência. Considerando a morosidade da justiça e a complexidade desse fenômeno da violência conjugal contra mulheres cometida por homens, muitas delas ainda estavam envolvidas nos processos judiciais e, por vezes, ainda se utilizando de medidas protetivas. Por se tratar de um tempo curto de separação, é possível que não tenha sido contemplada a totalidade do fenômeno, sendo possíveis outras percepções quando decorrido mais tempo desde o final do relacionamento.

Por fim, a violência conjugal contra mulheres cometida por homens é reconhecida como um fenômeno amplo e complexo que envolve múltiplos fatores. Surge assim a necessidade de uma compreensão e atenção integrada, com a articulação de diferentes perspectivas e em diferentes âmbitos para seu enfrentamento. Portanto, a articulação dos programas deve estar em consonância com o contexto e momento em que essas mulheres e homens estão vivenciando essa relação, atuando em uma efetiva mudança.

\section{REFERÊNCIAS}

Barding, L. (2009). Análise de Conteúdo. Lisboa: Edições70.

Casique, L. \& Furegato, A. R. (2006). Violência contra mulheres: reflexões teóricas. Revista Latino-Americana de Enfermagem, 14(6), 137-144. doi: 10.1590/ S0104-11692006000600018.

Dutra, M. L., Prates, P.s Nakamura, E., \& Villela, W. V. (2013). A configuração da rede social de mulheres em situação de violência domés-
Mulheres que vivenciaram violência conjugal: concepções 10 sobre suas ações, o homem autor $\mathrm{e}$ a experiência

Paola Rodegheri Galeli

Clarissa De Antoni 
tica. Ciência \& Saúde Coletiva, 18(5), 1293-1304. doi: 10.1590/ S1413-81232013000500014

Falcke, D., Boeckel, M. G.y Arpini, D. M.s \& Madalena, M. (2015). Violência conjugal: em marido e mulher se mete a colher? In: A. Wagner, C. R. Mosmann \& D. Falcke. Viver a dois: oportunidades e desafios da conjugalidade (pp. 79-99). São Leopoldo, RS: Editora Sinodal.

Falcke, D., Oliveira, D. Z., Rosa, L. W., \& Bentancur, M. (2009). Violência conjugal: um fenômeno interacional. Contextos Clínicos, 2(2), 81-90. doi:10.4013/ctc.2009.22.02

Flick, U. (2009). Introdução à pesquisa qualitativa. Porto Alegre: Artmed.

Fonseca, R. M. G. S. (1997). Espaço e gênero na compreensão do processo saúde-doença da mulher brasileira. Revista Latino Americana de Enfermagem, 5(1), 5-13. doi: 10.1590/ S0104-11691997000100002

Gomes, N. Pry Garcia, T. C. S., Conceição, C. R., Sampaio, P. 0., Almeida, V. C., \& Paixão, G. (2012). Violência conjugal: elementos que favorecem o reconhecimento do agravo. Saúde em Debate, 36(95), 514-522. doi: 10.1590/ S0103-11042012000400003

Guimarães, F. L. \& Diniz, G. R. S. (2017). Masculinidades, anestesias relacionais e violência conjugal contra mulher. In A. Beiras \& M. Nascimento, Homens e violência contra a mulher: pesquisas e intervenções no contexto brasileiro (pp. 82-113). Rio de Janeiro: Instituto Noos.

Hutz, C. S. \& Zanon, C. (2011). Revisão da adaptação, validação e normatização da escala de autoestima de Rosenberg. Avaliação Psicológica, 10(1), 41-49.

Minayo, M. C. S. (2010). O desafio do conhecimento. São Paulo: Hucitec.

Miranda, M. P. M.s Paula, C. S., Bordin I. A. (2010). Violência conjugal física contra a mulher na vida: prevalência e impacto imediato na saúde, trabalho e família. Revista Panamericana de Salud Publica, 27(4), 300-308. doi: 10.1590/S1020-49892010000400009

Myers, D. G. (2014). Psicologia social (10 ed). Porto Alegre: Artmed.

Organização Mundial da Saúde - OMS. (2002). Relatório mundial sobre violência e saúde. Brasília, DF: Autor.

Schraiber, L. B., D'Oliveira, A. F. P. L., Couto, M. Te, Hanada, H., Kiss, L.B., Durand, J. G. et al. (2007). Violência contra mulheres entre usuárias de serviços públicos de saúde da Grande São Paulo. Revista de Saúde Pública, 41(3), 359-367. 10.1590/ S0034-89102007000300006

Shavelson, R. J. \& Bolus, R: (1982). Selfconcept: The inter-play of theory and methods. Journal Educational Psychology, 74(1), 3-17.

Silva C. D., Gomes, V. O., Acosta, D. F. Barlem, E. D.s \& Fonseca, A. D. (2013). Epidemiologia da violência conjugal: características do agressor e do ato violento. Revista de Enfermagem (UFPE), 7(1), 8-14. doi: 10.5205/ reuol.3049-24704-1-LE.0701201302

\section{PAOLA RODEGHERI GALELI}

Psicóloga - Universidade Federal de Ciências da Saúde de Porto Alegre.

E-mail: paola.rga@gmail.com

\section{CLARISSA DE ANTONI}

Doutorado em Psicologia, Mestrado em Psicologia do Desenvolvimento, Especialização em Psicologia Social. Professora Associada I - Universidade Federal de Ciências da Saúde de Porto Alegre.

E-mail: clarissad@ufcspa.edu.br 